\title{
Natural Frequencies Reduction of RC Slab Subjected to Incremental Concentrated Loads
}

\author{
Mezgeen S. Ahmed ${ }^{1}$, Abdulhameed A. Yaseen ${ }^{1}$, Fouad A Mohammad ${ }^{2}$ \\ ${ }^{1}$ College of Engineering, University of Duhok \\ ${ }^{2}$ School of the Architecture, Design and the Built Environment, Nottingham, Trent University, UK
}

\begin{abstract}
Reinforced concrete slabs are frequently used in many engineering structures such as buildings and bridges. Damages in an engineering structure including reinforced concrete slab are classified as light, moderate, and severe cracks. A special treatment is required for every typical crack-damage to strengthen its structure. The reinforced concrete slab experiencing cracks reduce stiffness as well as its strength. An experimental program was set up to establish a relation between cracks and changes of a dynamic system characteristics of the slab through natural frequencies. The aim is to perform experimental modal analysis (EMA) as a non-destructive vibration testing method for diagnosing the structural integrity of the slab. For this purpose, two RC square slabs specimens of dimensions $1200 \mathrm{~mm} \times 1200 \mathrm{~mm} \times 40 \mathrm{~mm}$ were used. As a first part of the project, a reinforced concrete slab was subjected to an increasing partially concentrated loads at the slab's center to introduce cracks. After each incremental load steps (5, $10,12 \mathrm{kN}$ ) the slab was unloaded. Then, a free-free set-up for the slab was established by using the flexible elastic ropes (bungee cords). After the dynamic test of 5, 10 and $12 \mathrm{kN}$ loads, the slab was strengthened using external CFRP sheets (type TR30S). Next, experimental modal analysis was performed to establish a relation between cracks and changes in natural frequencies of the slab. The overall trend of frequency decrease after occurring damage that would be expected for all modes. However, it is not guaranteed all modes have same sensitivity to the applied load that inflicts severe cracks.
\end{abstract}

KEYWORDS : Cracks, Dynamic characteristics, Modal analysis, Natural frequencies, Non-destructive tests (NDT).

\section{INTRODUCTION}

In accordance with demands and desires of the mankind, civil engineering applications have been improving throughout the history. It can be seen that with the advent of reinforced concrete (RC) technology, reinforced concrete structures such as buildings and bridges have become the majority of existing structures. Earlier, design of RC structures was limited to gravitational loads (based on dead loads and live loads) or could add other arbitrary loads. While recently, dynamic analysis and design have taken into

Academic Journal of Nawroz University

(AJNU) Volume 8, No 3 (2018).

Regular research paper : Published 21 August 2019

Corresponding author's e-mail : mezgeen.s@gmail.com

Copyright $@ 2017$ Mezgeen S. Ahmed 1, Abdulhameed A.

Yaseen ${ }^{1}$ and Fouad A Mohammad ${ }^{2}$

This is an open access article distributed under the Creative

Commons Attribution License. consideration in RC structures realm. The dynamic analysis and design of RC structures have been an objective of many researchers and designers. Predominantly, RC structures are subjected to extreme dynamic loads conditions due to any reason such as impact, blast, or earthquake (Selçuk Saatcı, 2007). Therefore, different types of load combinations can be taken into consideration in the course of designing these structures because service loads, environmental, accidental actions, as well as aging, may cause an adverse effect to structural members. With the aim of avoiding disasters from happening, regular inspection and condition assessment of civil engineering structures are required to be performed. So that early detection of any damage can be made whereby the reliability of the structures can be judged. In addition, early damage detection allows maintenance support and repair works 
to be fitly programmed, thereby minimizing the costs (Peeters et al., 1996). Detecting damages and their locations has an important role to help the competent engineers to make a conscious decision regarding the retrofit or replacement of damaged member or even the entire structure (Chen et al., 2006). As a consequence, assessment of the integrity of engineering components and structures is becoming increasingly important for both economic and safety reasons. Imperfections are often complicated to be detected, can result in failures that have destructive consequences far beyond a commercial cost. Therefore, a high importance is required to be paid to such topic area. The Nondestructive Testing (NDT) technique is a highly effective way to detect the smallest imperfection in civil engineering and industrial components before or even during their operational life. In the past decades, a dozen of NDT methods have been used in different fields of engineering, and they were well summarized by Raj et al. (1995). Damage or imperfection are detected by the most common Non-destructive methods, either visual or spotted methods. It is worthwhile to mention that visual inspections fail to assess the damage at early stages or when it is situated in hidden or internal areas (Meruane and Heylen, 2008). There exist several various non-destructive methods to diagnose defects in structures such as the ultrasonic or acoustic method, magnetic field method, radiography method, thermal field method and eddy current method. Most of these methods are restricted to limitations because the vicinity of damage must be known a priori, and the portion of the structures that is being inspected is readily accessible (Doebling et al.1998). The damage near or exactly on the surface of the structures can be detected through these experimental methods. However, in most fields of engineering such as civil, aerospace and mechanical engineering communities, previous knowledge about an area of damage or information related to damage is usually unknown before damage identification. Consequently, there is a need to have additional global damage detection methods as more powerful tools to overcome the deficiency of the aforementioned experimental methods. Non-Destructive Testing (NDT) methods based on various physical principle and; therefore, the capacity of some of them are limited for detecting damages and their locations. Accordingly, there is a growing interest in the application of more sophisticated non-destructive evaluation tool that is vibration-based damage detection methods. These methods are sufficiently sensitive to detect imperfections when they are situated in hidden or even internal areas of the inspected members. Such methods rely on the fact that loss of integrity or occurrence of damage in civil engineering and industrial components leads to alerts the structural (mass, stiffness or damping) properties. The alertness can be known and described through modal parameters such as frequencies (Eigenvalue), mode shapes (Eigenvectors) and modal damping rates (Peeters, 1996). Several methods have been implemented to detect damage using modal parameters; they were thoroughly reviewed and summarised by Carden and Fanning (2004) and Doebling et al. (1998). The most widely adopted experimental approach is an experimental modal analysis (EMA) method (modal testing) method. Experimental modal analysis EMA has become a significant topic in the field of structural assessment in civil and mechanical engineering (Zonta, 2000). The last few decades thus witnessed tremendous interests in the scientific understanding of the structural dynamic behaviour, and identifying modal parameters. Such field of scientific research is referred to as EMA, which has been extensively reviewed by Maia and Silva (1997); 
Ewins (2001); $\mathrm{He}$ and $\mathrm{Fu}$ (2001); and excellent vulgarization has been provided by Schwarz and Richardson (1999). It is important to mention that EMA relies on two critical assumptions, for instance, linearity and time invariance of the structure. Ozdoganlar et al., (2005) mentioned that the knowledge of EMA is employed for dynamic characterization of different types of engineering systems for various purposes. Firstly, validation, correction, and refining of analytical and computational models. Secondly, determination of energy dissipation capacity, i.e., the damping. Thirdly, derivation of simplified representative dynamic models of complex systems within the frequency range of interest. Then, detection and characterization of structural faults and defects, and next, determination of operational characteristics and fatigue behavior of structures. The excitation of the structure using EMA technique is via function of known frequency characteristics, for instance, impulse, random, and periodic using a shaker or an impact hammer. The relative pros and cons of the excitation method of shaker excitation versus modal hammer excitation have been reviewed by Reynolds and Pavic (2000). When the structure is excited, its associated response is simultaneously measured using the vibration sensor. Mostly, the vibration sensor is an accelerometer transducer, but occasionally a displacement transducer may be employed. Accelerometers are fixed to the structure via a threaded stud, which attaches on the surface of the structure by cement, wax or even magneto static forces depending on the quality of the tested materials (Labonnote, 2012).

\section{Methodology}

\subsection{Frequency Response Function}

A description of system characteristics is obtained by establishing Frequency Response Functions (FRFs). FRFs is expressed in the following equation which is the ratio of auto power spectral density to cross spectral density functions (McConnell and Varoto, 2008). Frequency response functions commonly presented in the form of motion over force.

$$
H \operatorname{pq}(\omega)=\frac{X_{p}(\omega)}{F_{q}(\omega)}
$$

Where :

$\operatorname{Hpq}(\omega)$ is the frequency response $\mathrm{Xp}(\omega) \quad$ is the output response (motion) $\mathrm{Fq}(\omega) \quad$ is the input (or forcing function)

$\mathrm{q}$ and $\mathrm{p}$ are the input and output degrees-of-freedom respectively.

Resonance frequency is the easiest modal parameter to be reliably obtained. Estimation of the resonance frequency of a structure is considerably important and is directly calculated from FRF. A resonance frequency is identified as the highest amplitude in the magnitude of the FRF, and the frequency corresponding to the specific peak represents the resonance frequency $(\omega)$ of that mode of vibration. The FRF of the slabs were extracted using the Matlab code. From the FRF, the natural frequencies of $\mathrm{RC}$ slabs in this work related to each parametric study are extracted. The estimated natural frequencies of all four status are shown in Table1.

\subsection{Theoretical Review}

The analytic closed form formula giving angular natural frequencies of a RC slab of length $\ell$ and width $b$, freely supported with uniform cross section is widely available in literature, 
using standard notations that as indicated below (Blevins, 2001) :

$$
f=\frac{\lambda^{2}}{2 \pi \cdot l \cdot b} \sqrt{\frac{D}{\mu}}
$$

$$
D=\frac{E h^{3}}{12\left(1-0.24 v^{2}\right)}
$$

Where :

$\mathrm{f}$ is the natural frequency in $\mathrm{Hz}$

Dis the plate flexural rigidity

$\mathrm{E}$ is modulus of elasticity

$v$ is the Poisson's ratio of the material of the plate

$\mu$ is the mass density per unit area of plate $(\rho h)$

$\rho$ is the density of the material making the plate

$\mathrm{h}$ is the thickness of the plate

$\lambda$ is a dimensionless natural frequency factor for freely and simply supported slabs.

The natural frequencies of freely RC square slabs can be obtained using above equations. It can be said that analytical solution has some important benefits. First, relatively small computational time and effort are required to get an idea of the behavior of the structure. Second, analytical method can be used to know the reliability of the numerical results.

\subsection{Experimental work}

After 28 days of casting the RC slabs, the slabs were appropriately cured. After proper hardening, the two RC slabs were separately setup for doing tests. Both static and dynamic tests were performed in this study in order to achieve the intended purpose.

\section{A. RC slab description}

The specimens consist of two reinforced concrete slabs with a thickness of $40 \mathrm{~mm}$ and cross-sectional area of $1200 \times 1200 \mathrm{~mm}$. The used concrete had a mean 28-days compressive strength of about $30 \mathrm{MPa}$ based on the 100 $\mathrm{mm}$ cube tests. In each direction, the slabs were reinforced with 20 steel bars of diameter $6 \mathrm{~mm}$, equally spaced over tension zone, which corresponds to a reinforcement ratio of about $1.18 \%$. Peeters et al. (1996) recommended that the reinforcement ratio should be within a realistic range in modal analysis. The proper choice of the quality of the reinforced bar, dimensions and properties of the structure are considerably important. These factors have direct roles on the interval between cracking and failure states of the structure. Interval between onset of cracking and structure failure can be made quite enough and essential to allow modal analysis at well-separated levels of cracking.

\section{B. Experimental set up and procedure}

$\mathrm{RC}$ slabs should be gradually damaged in order to find the effect of degree of damages on modal parameters of the RC slabs. As previously mentioned that, the slabs were set up for both static and then dynamic tests. Both static and dynamic tests were performed in this study in order to achieve the intended purpose. The former test was used in order to damage the RC slabs. While the latter test was performed in order to identify the effects of damages on natural frequencies of the slabs. The testing procedure of the two tests can be described as follows. The slab was simply supported at all four sides. A rubber pipe and High Impact Polystyrene (HIPs) were set on the top of the metal support around all edges, which were the contact lines between the slab and the support in order to fill probable gaps in between the slab and the support as described in Figure1. 


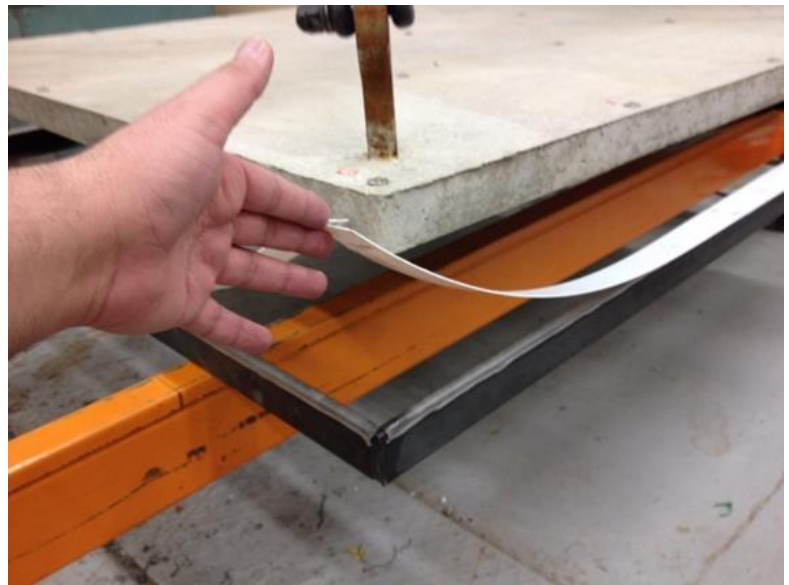

Fig (1) : Rubber pipe and HIPs been placed onto the support contact line

To apply the partially concentrated monotonic load, a metal square of dimensions $120 \times 120 \times 20 \mathrm{~mm}$ was placed at the top face of the slab center where the concentrated load was going to be applied. The purpose of applying partially concentrated load condition was to make large enough interval allow modal analysis at well-separated levels of cracking without occurrence any shear failure mechanism. Partially concentrated load with a constant rate of loading to introduce different degree of damages was employed during the test. Figure 2 illustrates static testing setup. The partially concentrated load was gradually applied at the centre of the slab using a hydraulic jack. Both the hydraulic jack a Linear Variable Displacement Transducer (LVDT) were monitored to a data logger to display the load and deflection. Applying monotonic loading with a hydraulic jack resulted in an increasingly damaged slab. At each prescribed loading step $(5,10$, $12 \mathrm{kN}$ ), the deflection was read using LVDT. Then, the slab was unloaded and gently put on its side; after that its bottom surface was cleaned in order to inspect progressive crack pattern visually.

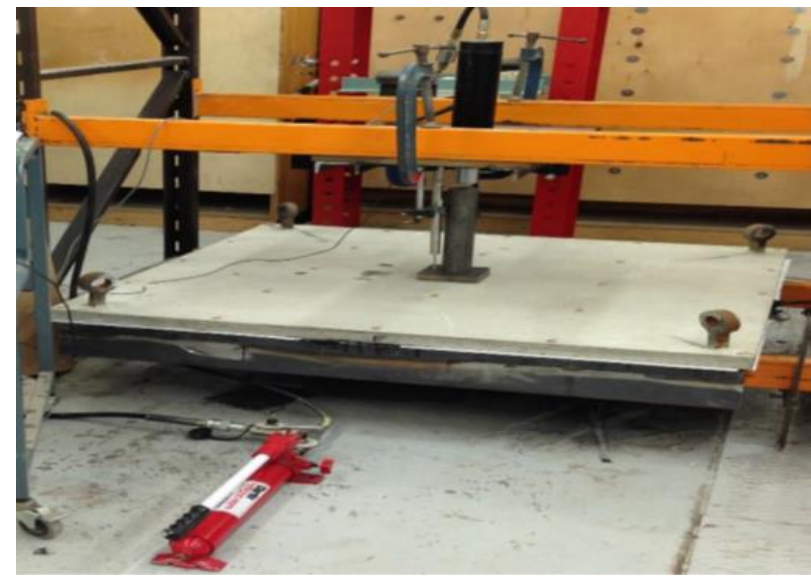

Fig (2) : RC slab under partially concentrated load After each unloading and inspecting steps, the slab was suspended by flat webbing slings to simulate a free-free boundary condition In order to avoid influences of supports on responses of specimen. Figure 3 shows the properly suspended slab; it was subjected to an experimental modal analysis, which is the dynamic test portion.

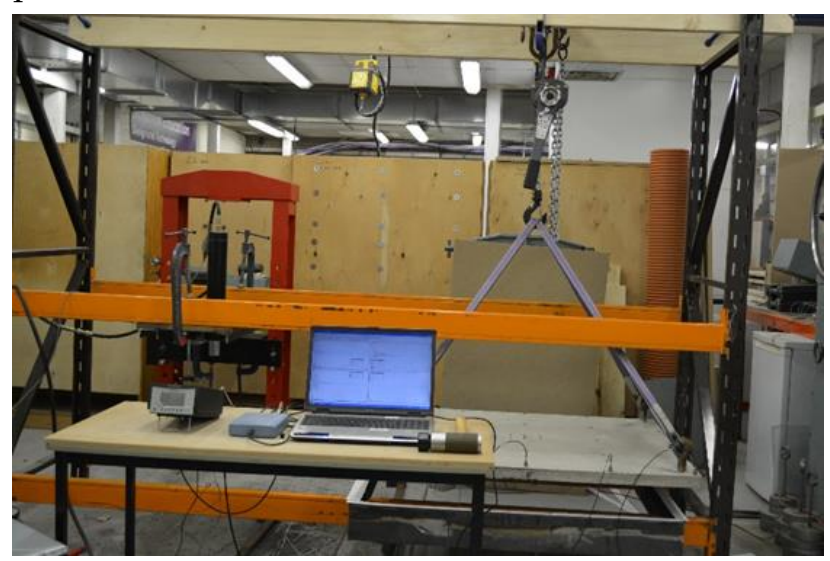

Fig (3) : Test slab under free-free boundary condition

Accelerometers were mounted on the slab surface. The slab was excited by a dynamic force which is generated by means of an impact hammer in the top surface of one point of slab's corner. Whereas, accelerometers were used to measure the vibration responses. For obtaining more accurate results, a hammer impact test was repeated five times for obtaining the responses. It is worth noting that an experimental modal analysis was firstly performed on the undamaged (intact) state of the 
slab. EMA of intact slabs is important because the results of intact slabs serve as a reference specimen for later comparison of dynamic characteristics at the different damage states (under $(5,10,12 \mathrm{kN})$. After the final load test, $12 \mathrm{kN}$, the slab was repaired as the defective zone strengthened by bonding external CFRP sheets (type TR30S) of $1200 \mathrm{~mm}$ long and $100 \mathrm{~mm}$ width. The slab was removed and its tension face was properly cleaned of dust and debris to reduce their effect on the bonding between the adhesive epoxy and the concrete. Once the slab was cleaned, three zones each of which had $100 \mathrm{~mm}$ wide and $1200 \mathrm{~mm}$ long were defined on the tension face in both directions in the middle of the slab. These marked areas are the positions where the CFRP sheets will be placed, as shown in Figure 4. The 105 epoxy resin and 205 hardener mixture was prepared in required amount. The mixture had a ratio of $5: 1$ (resin : hardener). After the mixture was well stirred for few minute, it was then applied to the marked positions on slabs underneath. The CFRP fabrics was then applied to the marked position as soon as the resin was applied. It was placed on position in vertical and horizontal direction, over lapping one another, to make an interlock interlace one to the other. Slabs was then left to dry for at least 24 hours to harden completely. After it was checked that the bonding agent was dried, it was then tested dynamically to extract the modal parameters.
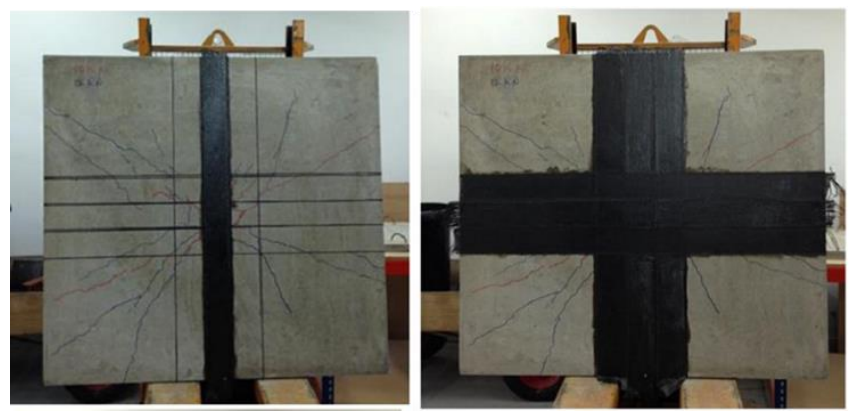

Fig (4) : Required steps for bonding CFRP on the slab

\section{Instrument}

The used instruments in this study were the DeltaTron ${ }^{\circledR}$ impact hammer version 8208 (By a proper choice of the hammer tip, it is possible to generate a reasonable response); an accelerometer DeltaTron ${ }^{\circledR}$ model 4514. In addition, NEXUSTM type 2690 conditioning amplifier was used during this study to boost the slight electrical charge, signals. The data acquisition card, Pico Scope 4424, was also employed to convert the captured analogue to a digital signal (A/D conversion). Moreover, personal computer with signal processing software such as MATLAB ${ }^{\circledR}$ were also required to analyze the data.

\section{EXPERIMENTAL RESULTS AND DISSCUTION}

\section{A. Static test results}

The partially concentrated load tests were conducted on the two slabs for introducing cracks. After preparing a specimen, $5 \mathrm{kN}$ was applied to the slab, and afterwards slab was unloaded for performing modal test. The same process was implemented for another two incremental loads (10 and 12kN). During the test, both loading and mid-span deflection of the RC square slab were automatically recorded. In addition, at the end of each load step, the slab surface was visually inspected to locate as well as quantify the cracks. One hair crack at the tension zone of the slab was visible at a static load of $5 \mathrm{kN}$. The hair crack was extended, and some others were appeared at the load $10 \mathrm{kN}$. These cracks were in discontinuous lines and moved towards the corners. These cracks were developed and moved in relatively straight lines towards the two corners of the slab at the load $12 \mathrm{kN}$. It was not desired to increase the load beyond $12 \mathrm{kN}$ because the slab was strengthened and used for dynamic test.

\section{B. Dynamic test results}

Dynamic test was performed on both intact and damaged states of the slab. The identified dynamic 
characteristics of intact results serves as a reference for comparison of dynamic characteristics at the different damage states. The comparison of the experimental modal parameter (natural frequencies) of the slab obtained in successive damage and repaired states as described below. These parameters were obtained from a set of FRF measurements. As aforementioned, a description of system characteristics is obtained by establishing Frequency Response Functions (FRFs). Frequency response functions commonly presented in the form of motion over force. From a set of FRF, modal parameters can be extracted from a number of measurements. It is worth mentioning that a natural frequency of the structure can be extracted from any FRF measurement. At resonance, the magnitude of FRF rapidly approach a sharp maximum value, which demonstrate the number initial separable natural frequencies of modes of motion (Ewins, 2000). In this work, six corresponding natural frequencies (for modes 1, 24,68 and 10) obtained are presented.

\section{Discussion of Results}

The most popular modal property used to alert the presence of damage is the natural frequencies of the structure. Frequencies of various modes can be obtained by the excitation and receiving a response at any degree of freedom for the entire structure. When a structure is subjected to a certain degree of damage or deterioration, it experiences a change in stiffness that it causes the natural frequency to change (Salawu, 1997; Saleh et al, 2004; Daneshjoo and Gharighoran, 2008). The researchers believe and widely accept that the magnitude of the changes of natural frequency can be utilized as an indicator of the severity or state of the damage experienced. The discrepancy is apparent in the changes in the natural frequencies of the damaged slabs as compared to the reference state. For the test slabs, the values of the natural frequencies of the test stages were determined. Table 1 shows the results of natural frequencies of six modes of slabs under five different damage scenarios (intact, $5 \mathrm{kN}, 10 \mathrm{kN}, 12 \mathrm{kN}$ and repaired). After averaging the natural frequencies of both slabs, the shift in natural frequencies is depicted in Table 2. The percentage of reduction in natural frequency for each stage is defined as the percentage of difference between natural frequencies of the intact and defective slabs.

Table (1) : Experimental natural frequencies of RC slabs (1 and 2), under different status

Average of both slabs 1 and 2 (1200x1200x40)

\begin{tabular}{|c|c|c|c|c|c|}
\hline $\begin{array}{c}\text { Load } \\
\text { step } \\
\text { Mode } \\
\text { No. }\end{array}$ & $\begin{array}{c}\text { Intac } \\
\mathbf{t}\end{array}$ & $\mathbf{5 k N}$ & $\mathbf{1 0 k N}$ & $\mathbf{1 2 k N}$ & Repaired \\
\hline 1 & 75.4 & 72.9 & 57.9 & 55.0 & 62.3 \\
\hline 2 & 112.3 & 102.9 & 87.5 & 78.7 & 92.8 \\
\hline 4 & 171.0 & 154.0 & 114.3 & 97.71 & 127.0 \\
\hline 6 & 282.4 & 279.1 & 231.9 & 209.8 & 237.8 \\
\hline 8 & 301.1 & 292.6 & 256.7 & 231.4 & 253.0 \\
\hline 10 & 319.4 & 314.0 & 283.9 & 265.3 & 281.1 \\
\hline
\end{tabular}

The frequencies of the defective slabs decrease after damage occurs due to first, penultimate and final load level. Figure 5 illustrates the drops in the six natural frequencies for each loading condition from the reference intact case for slab. 


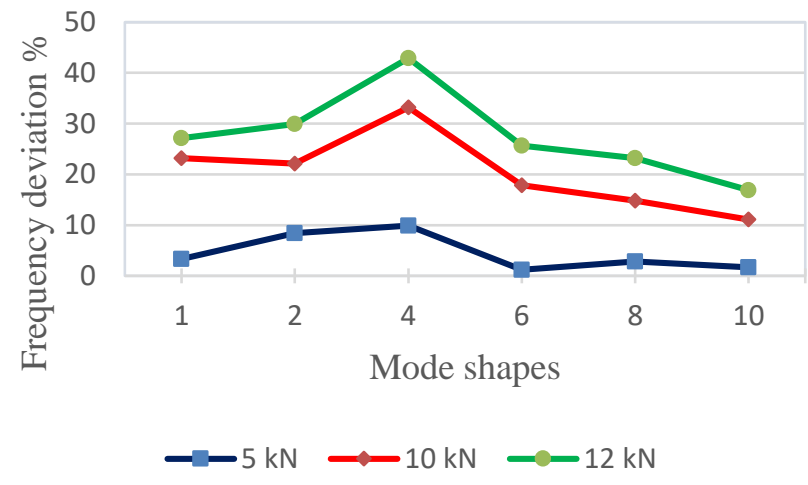

Fig (5) : Drops in natural frequencies of RC slabs under different loading levels.

When the samples were initially loaded to $5 \mathrm{kN}$ and then unloaded, hair crack initiation was seen in the bottom of the slab. Then the dynamic test was performed and the data was analyzed and then the natural frequencies for each defective stage compared with the intact case. Drop in natural frequencies under $5 \mathrm{kN}$ for all modes is low when compared to penultimate and final load levels, see second column of Table 2.

Table (2) : Deviation in natural frequencies of RC slabs, under different status.

\section{Reduction in frequencies due to incremental loads}

\begin{tabular}{|c|c|c|c|c|c|}
\hline $\begin{array}{c}\text { Load step } \\
\text { Mode No. }\end{array}$ & Intact & $\mathbf{5 k N}$ & $\mathbf{1 0 k N}$ & $\mathbf{1 2 k N}$ & Repaired \\
\hline 1 & 0.0 & 3.3 & 23.2 & 27.1 & 13.3 \\
\hline 2 & 0.0 & 8.4 & 22.1 & 29.9 & 17.9 \\
\hline 4 & 0.0 & 9.9 & 33.2 & 42.9 & 29.9 \\
\hline 6 & 0.0 & 1.2 & 17.9 & 25.7 & 13.4 \\
\hline 8 & 0.0 & 2.8 & 14.8 & 23.2 & 9.3 \\
\hline 10 & 0.0 & 1.7 & 11.1 & 16.9 & 5.9 \\
\hline
\end{tabular}

Drop in natural frequencies under $10 \mathrm{kN}$ and $12 \mathrm{kN}$ can be observed in third and fourth columns of Table 2 respectively. During the penultimate incremental loading, $10 \mathrm{kN}$, the cracks were observed to increase in length and width. Due to the significant flexural cracks emerged in the slab's underneath; the loading process was stopped, at $12 \mathrm{kN}$, before the ultimate load is reached. It is worth pointing out that the maximum load of the last loading cycle was decided to be corresponding to the analytical ultimate load with respect to flexural resistance of $\mathrm{Pu}=18 \mathrm{kN}$ and maximum $\mathrm{P}=10.25 \mathrm{kN}$ may put this between loading and repairing. It is evident that applying a load on the specimens gives energy for the crack initiation and propagation process. Crack initiation and subsequent growth happened quite readily due to increasing the load to $10 \mathrm{kN}$. This means that the one hair crack was diagonally initiated at first load level, 5kN. Such crack started to open and developed diagonally to toward the edge of the slab with initiation some other cracks at load level $10 \mathrm{kN}$. As can be seen in this figure, at penultimate load level which is $10 \mathrm{kN}$, the drop in natural frequencies for the first, second and fourth modes is quite significant $23.2 \%, 22.1 \%$ and $33.2 \%$ compared to the drop in early stage load level, $5 \mathrm{kN}$. The reduction can be seen in modes sixth, eighth and tenth are about $17.9 \%, 14.8 \%$ and $11.1 \%$ respectively. This trend is suggested that the first, second and fourth modes of vibration of the slab is more influenced by the crack pattern than higher modes. Furthermore, the drop in natural frequencies for all modes of penultimate load level is higher when compared to the $5 \mathrm{kN}$ load levels. Before close to the ultimate load stage $(\mathrm{P}=12 \mathrm{kN})$, drops of $27.1 \%, 29.9 \%$, $42.9 \%, 25.7 \%, 23.2 \%$ and $16.9 \%$ were observed for the frequencies of first, second, fourth, sixth, eighth and tenth mode respectively. The reduction in natural frequency of this condition can be divided into typically two regions, that is, increased the reduction from mode 1, 2 and 4, while it is decreased from 4, 6, 8 and 10 
respectively. This means that a notable observation is drawn as $42.9 \%$ drop in the fourth frequency (corresponding to $12 \mathrm{kN}$ load) was obtained. As is seen in natural frequency trends, the frequency reduction of the fourth mode increased significantly responding to the increasing damage. From the crack patterns in general, it was obvious that the situation was closed to the ultimate load that is why it was stop to apply further loads on the slab in order to avoid the formation of the yield line. Although the slabs sections were visually in an imperfection condition, a percent of $13.3 \%, 17.9 \%, 29.9 \%, 13.4 \%, 9.3 \%$ and $5.9 \%$ of frequency deviation was recovered for the six frequencies when the slab was repaired by using CFRP. It is notable that, the rate of recovery was higher for the fourth mode since the modification likewise the deterioration affected heavily the fourth modes as shown in Figure 6. This means the rate of recovery of CFRP sheets in the natural frequencies appears to increase as the damage increases.

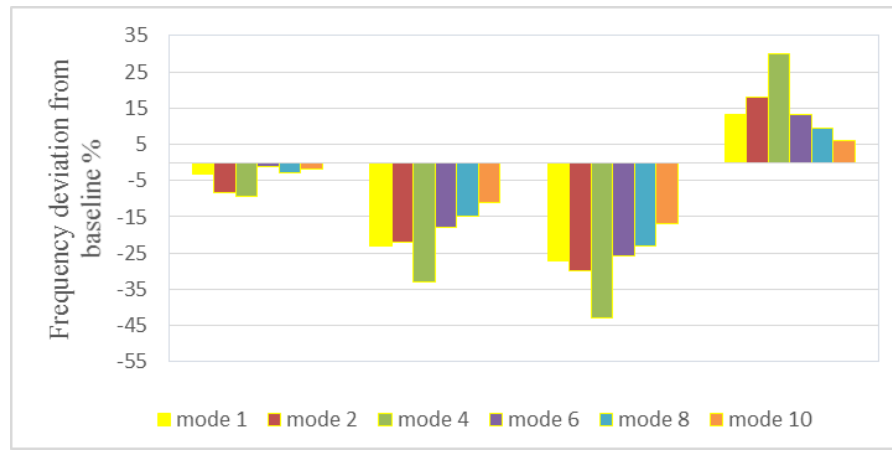

Fig (6) : Natural frequencies deviations of RC slabs, under different conditions.

It is observed that natural frequencies in all modes are continuously decreasing for average of slabs compare to their previous states due to gradual load increment. Similar trend has been also observed in the work of previous researchers as well who were testing RC beams (Peeters et al. 1996; by Al-Ghalib, 2013). It is also concluded in this study that the rate of recovery of
CFRP sheets in the natural frequencies appears to increase as the damage increases.

\section{CONCLUSION}

Two reinforced concrete slabs were subjected to an increasing static load in order to introduce cracks. The evolution of the dynamic characteristics of the slabs through the different damage states were described. The natural frequencies of the slabs were identified using EMA. The overall trend of frequency decrease after occurring damage that would be expected for all modes. However, it is not guaranteed all modes have same sensitivity to the applied load that inflicts severe cracks. On the whole, the variation in natural frequencies corresponds to the severity of inflicted damage due to unusual reasons. The variation in natural frequencies can be used as one useful indicator to identify the presence of damage but not for assessing the extent of damage in reinforced concrete slabs precisely. It is observed that natural frequencies in all modes are continuously decreasing for average of slabs compare to their previous states due to gradual load increment. It is concluded that the rate of recovery of CFRP sheets in the natural frequencies appears to increase as the damage increases.

\section{ACKNOWLEDGMENT}

The experimental data come from the reinforced concrete slab tests performed at the Laboratory of the design, and build environment of Nottingham Trent University, UK. Therefore, the authors would like to thank the technicians for their help during the experiments.

\section{REFERENCES}

1. AL-Ghalib, A., A. (2013). Damage and repair identification in reinforced concrete beams modelled with various damage scenarios using vibration data. PhD thesis. Nottingham Trent University.

2. American Concrete Institute (ACI318 : 11), (2011). Building 
Code Requirements for Structural Concrete and Commentary, Farmington Hills, MI, USA

3. Blevins, R. D. (2001). Formulas for natural frequency and mode shape. Krieger Pub. California 95327.

4. Carden, E. and Fanning, P., (2004), "Vibration Based Condition Monitoring : A Review". Structural Health Monitoring, 3(4) : PP.355-377.

5. Chen, G., Yang, X., Ying, X. and Nanni, A. (2006). Damage detection of concrete beams using nonlinear features of forced vibration. Structural Health Monitoring vol 5 (2), PP. 125-141. 6. Daneshjoo F, Gharighoran A. (2008). Experimental and theoretical dynamic system identification of damaged RC beams, Electronic Journal of Structural Engineering. 8, PP. 2939.

7. Doebling, S.W., Farrar, C.R., and Prime, M.B., (1998) “A Summary Review of Vibration-Based Damage Identification Methods," The shock and Vibration Digest, vol. 30, No. 2, March 1998, 91-105.

8. Ewins, D.J. (2000). Modal Testing : Theory, Practice and Application. 2nd ed. Baldock, England : Research Studies Press. 562.

9. Labonnote, N. (2012). Damping in Timber Structures. A thesis submitted for the Degree of Doctor of Philosophy in Engineering, Norwegian University of Science and Technology Faculty of Engineering Science and Technology Department of Structural Engineering, Norway.

10. Liu, Y., Chandra, J., and Teng, S. (2011). Shear analysis of reinforced concrete slabs with effective moment of inertia. Proceedings of the 36th Conference on Our World in Concrete \& Structures, Singapore.

11. Maia N., Silva J., He J, Lieven N., Lin R., Skingle G., To W-M And Urgueira A. (1997). Theoretical and Experimental Modal Analysis. Editors : Maia and Silva, UK : Research Studies Press Ltd., Taunton, Somerset, England.

12. McConnell K and VAROTO P (2008). Vibration Testing : Theory and Practice. John Wiley \& Sons, Inc., USA.

13. Meruane, V. and Heylen. W., (2008). Damage detection on a multi-cracked beam by parallel genetic algorithms using modal characteristic. Proceedings of the International Conference on Noise and Vibration Engineering, ISMA, Leuven, Belgium.

14. Ozdoganlar, O. B., Hansche, B. D., and Carne, T. (2000). Experimental modal analysis for microelectromechanical systems. Experimental Mechanics, 45(6) : PP.498-506, 2005.

15. Peeters B., Abdel Wahab, M., De Roeck, G., De Visscher, J., De Wilde, W.P., Ndambi, J.-M. and Vantomme, J. (1996). Evaluation of structural damage by dynamic system identification.Proceedings of ISMA 21, the 21th International Seminar on Modal Analysis

16. Raj, B., Jayakumar, T., Rao, B. P. C., (1995).Nondestructive testing and evaluation for structural integrity. Sadhana. Volume 20, Issue 1, PP. 5-38.

17. Reynolds, P. and Pavic, A. (2000). Impulse hammer versus shaker excitation for the modal testing of building floors. Experimental Techniques. 24(3) : PP. 39-44.

18. Saatc1, S., (2007). Behaviour and modelling of reinforced concrete structures subjected to impact loads. A thesis submitted in conformity with the requirements for the degree of Doctor of Philosophy to civil engineering department, University of Toronto.

19. Salawu O. (1997). Detection of structural damage through changes in frequency : a review, Engineering Structures, 19. 718-23.

20. Saleh F, Supriyadi B, Suhendro B. (2004). Damage Detection in Non-Prismatic reinforced Concrete Beams Using Curvature Mode Shapes, Proceedings of the International Conference on Structural Integrity and Fracture. PP. 331-338.

21. Schwarz, B.J. and M.H. Richardson (1999). Experimental Modal Analysis. in CSI Reliability Week.. Orlando.

22. Vecchio, F.J. and Tata, M. (1999). Approximate analysis of reinforce concrete slabs", Structural Engineering and Mechanics, 8(1), 1-18.

23. Zonta, D., (2000). Structural damage detection and localization by using vibrational measurements. PhD dissertation, University of Bologna, Gennaio. 